Check for updates

Cite this: New J. Chem., 2020, 44, 13207

Received 29th May 2020, Accepted 6th July 2020

DOI: 10.1039/d0nj02716b

rsc.li/njc

\title{
Investigation of and mechanism proposal for solvothermal reaction between sodium and 1-(2-hydroxyethyl)piperidine as the first step towards nitrogen-doped graphenic foam synthesis
}

\author{
Lilian Moumaneix, ${ }^{a}$ Jenifer Guerrero Parra, ${ }^{a}$ Sébastien Fontana, (D) ${ }^{a}$ \\ François Lapicque ${ }^{b}$ and Claire Hérold (D) *a
}

\begin{abstract}
For the purpose of synthetizing 3-dimensional nitrogen-doped graphenic materials, which could be used as oxygen reduction catalysts in membrane fuel cells, a solvothermal-based route was successfully carried out. However, the solvothermal reaction between metallic sodium and 1-(2-hydroxyethyl) piperidine (HEP), with the latter as the source of both carbon and nitrogen, is still little understood. The present work was aimed at investigating the solvothermal process under different conditions of temperature and pressure and with different amounts of sodium. Use of in situ mass spectroscopy during the three-day reaction revealed the early formation of dihydrogen, as well as carbon oxides, methane and ammonia, in addition to fragments of ethylpiperidine alkoxide (EP-ONa). XRD measurements evidenced the formation of sodium-based compounds, e.g. hydride, carbonate, hydroxide, and cyanide. Interestingly, Raman spectroscopy revealed the significant presence of large aromatic molecules as well as an $\mathrm{sp}^{2}$ carbon network, an early precursor of graphene. Analysis of the overpressures and reaction yields suggests that the primary compound from the reaction of HEP with sodium is a large $\mathrm{sp}^{2}$ carbon-based network entrapping numerous sodiumbased molecules as well as a volatile liquid phase. The suggested reaction mechanism provides information to better tailor the solvothermal products, whose pyrolysis at $850{ }^{\circ} \mathrm{C}$ led to very high specific area nitrogendoped carbon materials.
\end{abstract}

\section{A. Introduction}

Supercritical fluids (SCF) provide distinctive experimental media, as their properties strongly depend on both their internal pressure and temperature. Halfway between gas and liquids states, supercritical fluids give great opportunities for control over many physical properties, e.g. reactivity, density, polarity or viscosity. ${ }^{1}$ SCF possess liquid-like densities $\left(0.2-0.9 \mathrm{~g} \mathrm{~cm}^{-3}\right)$, gaslike viscosities $\left(1-9 \times 10^{-5} \mathrm{~Pa} \mathrm{~s}^{-1}\right)$ and intermediate diffusivities $\left(2-7 \times 10^{-8} \mathrm{~m} \mathrm{~s}^{-1}\right){ }^{2}$

Technologies based on SCF are used daily in many industrial applications, such as the extraction of numerous organic molecules from agricultural products, e.g. aroma from plants and caffeine from coffee, cold sterilization, impregnation at the heart or plastic packaging treatments. In materials science, phenomena made possible by SCF media are of great interest

\footnotetext{
${ }^{a}$ Institut Jean Lamour, CNRS - Université de Lorraine, 2 allée André Guinier, 54011 Nancy, France. E-mail: claire.herold@univ-lorraine.fr; Fax: +33 372742537; Tel: +33372742537

${ }^{b}$ Laboratoire Réactions et Génie des procédés, CNRS - Université de Lorraine, ENSIC, 54000 Nancy, France
}

for the synthesis or post-treatment methods for numerous materials.

With regard to carbon materials, the literature contains several examples of SCF applied to process nanocarbon materials, including graphenic materials. Currently, graphene is widely studied in numerous scientific fields thanks to its electric, thermal, chemical and mechanical properties. Numerous operations can be achieved on carbon materials under SCF conditions, e.g. graphite exfoliation, ${ }^{3,4}$ synthesis of graphene composites, ${ }^{5}$ elaboration of three-dimensional graphenic materials ${ }^{6-8}$ or deposition of metal nanoparticles on graphene materials. ${ }^{9}$

In the last decades, various research works have focused on obtaining three-dimensional graphenic materials, such as crumpled graphene sheets, graphene frameworks and graphene foams, through solvothermal-based processes. A solvothermal reaction is defined as a reaction in a closed system between reagents in the presence of a solvent (which can be one of the reagents) at a temperature higher than the boiling point of the solvent. If both the pressure and temperature are above (below) those of the solvent's critical point, the solvothermal reaction is said in to be under supercritical (subcritical) conditions. 
In addition to allowing the reaction to occur at moderate temperatures, closed system processes also help reduce noxious emissions in the environment. ${ }^{10} \mathrm{~A}$ heat treatment is often needed after the reaction to convert the carbon-rich solvothermal product into well-organized graphenic materials. This route of synthesis allows the recovery of a substantial quantity of graphenic material and possesses good potential for scalability towards industrial processes. ${ }^{10}$ In 2004, Kuang et al. ${ }^{11}$ reported the fabrication of crumpled graphene nanosheets by the reaction between tetrachloromethane $\left(\mathrm{CCl}_{4}\right)$ and potassium in an autoclave heated at $60{ }^{\circ} \mathrm{C}$ for 10 hours. Eftekhari et al. ${ }^{12}$ adapted this synthetic route to produce curly graphene sheets by adding cobalt chloride, which acts as a catalyst to transform graphene sheets into carbon nanotubes. In parallel, several works dealt with oxidation reactions of sodium in contact with an alcohol, e.g. methanol, ethanol or butan-1-ol. ${ }^{13-17}$ In their study, Choucair et $a .^{13}$ synthesized crumpled graphene sheets using ethanol and sodium. The solvothermal reaction was carried out at $220{ }^{\circ} \mathrm{C}$ for $72 \mathrm{~h}$, followed by flash pyrolysis. They proposed a mechanism based on the encapsulation of free-ethanol by saturated metal alkoxide in a clathrate-like structure during the solvothermal reaction to explain the obtained structure. However, complementary investigations are required to confirm their original theory. Speyer et al. ${ }^{14-16}$ considered nearly the same process but applied 100 bar upon introduction of nitrogen into the reactor to further increase the pressure during the reaction. The resulting graphenic samples showed noticeable improvement in their crystallinity. These publications, and other works not cited here, display the possibility to transform small organic molecules into large $\mathrm{sp}^{2} 3$-dimensional graphenic networks using a convenient, highly adaptable technique.

Recently, nitrogen-doped carbon materials have attracted great attention due to their potential as critical metal-free catalysts, ${ }^{18-20}$ their semi-conducting properties or their capacity to provide good anchors for metal nanoparticle nucleation. ${ }^{21,22}$ Synthesized by arc-discharge-based synthesis, ${ }^{23}$ chemical vapor deposition (CVD), ${ }^{24}$ thermal treatment, ${ }^{25,}{ }^{26}$ metallothermic reduction ${ }^{27}$ or plasma treatment, ${ }^{28}$ high quality N-doped carbon materials can also be prepared through direct solvothermal-based synthesis. ${ }^{29-32}$ However, only a few examples of solvothermal synthesis of $\mathrm{N}$-doped graphenic materials have been reported so far. Tetrachloromethane $\left(\mathrm{CCl}_{4}\right)$ is a commonly used precursor when mixed with lithium nitride $\left(\mathrm{Li}_{3} \mathrm{~N}\right),{ }^{29} \mathrm{Li}_{3} \mathrm{~N}$ and cyanuric chloride $(\mathrm{NCCl})_{3},{ }^{30}$ or pyrrole $\left(\mathrm{C}_{4} \mathrm{H}_{5} \mathrm{~N}\right)$ and potassium. ${ }^{31}$ However, the formation of chlorine-derived gases could be avoided by changing the reagents and reaction conditions. In a previous study, ${ }^{33}$ a solvothermal-based process using a mixture of cyclohexanol, ethanolamine and sodium was developed for the synthesis of good quality nitrogen-doped graphenic foam, whose extensive characterization revealed high surface area, good crystallinity and promising catalytic properties. Moreover, this study allowed determination of the optimal temperature of pyrolysis, $850{ }^{\circ} \mathrm{C}$, to yield $\mathrm{N}$-doped graphenic foams with the best compromise between homogeneity, purity and crystallinity, along with appreciable synthetic yields.

The present paper focuses on the solvothermal reaction itself, which has been very little investigated until to now. For this pioneering work, it was preferable to consider the reaction of a single molecule as the source of $\mathrm{C}$ and $\mathrm{N}$ atoms, 1-(2hydroxyethyl)piperidine $\left(\mathrm{C}_{7} \mathrm{H}_{15} \mathrm{NO}\right)$, subsequently called HEP, and metallic sodium, here combined to form, after a subsequent pyrolysis treatment, high-quality nitrogen-doped graphenic foam. The variation of the solvothermal product with the reaction parameters was followed using complementary techniques to better understand the reaction mechanism involved here and more generally for carbon materials synthesis through solvothermal-based processes.

\section{B Materials and methods}

\section{B.1. Synthesis}

A mixture of $0.17 \mathrm{~mol}$ of 1-(2-hydroxyethyl)piperidine (ACROS organics, 99\%) was put into contact with a certain amount of metallic sodium (Merck Millipore) under inert atmosphere (nitrogen, Air Liquide, Alphagaz 2) in a 0.5 L Parr autoclave. The 1-(2-hydroxyethyl)piperidine was used as received. Sodium rods were washed in petroleum ether to remove the paraffin oil, then scraped before use to remove the passivation layer formed even under a protective atmosphere. The theoretical critical conditions of 1-(2-hydroxyethyl)piperidine have been estimated to be around $385 \pm 29{ }^{\circ} \mathrm{C}$ and $37 \pm 7$ bar using computational models. ${ }^{34-36}$ Thus, the solvothermal reaction was carried out at $300{ }^{\circ} \mathrm{C}, 350{ }^{\circ} \mathrm{C}$ and $380{ }^{\circ} \mathrm{C}$, with further increase in temperature avoided for technological reasons. The solvothermal reaction pressure was varied between 100 bar and 200 bar, a range which has been proved suitable for synthesis of high-quality graphenic materials in previous works. ${ }^{33}$ Once the autoclave was sealed, nitrogen (Air Liquide, Alphagaz 2) was introduced so that the internal pressure at the reaction temperature could reach the desired level of 100 bar or 200 bar. The reactor was then heated to the target temperature at $8{ }^{\circ} \mathrm{C} \min ^{-1}$ and the internal pressure reached the desired value. The mixture was reacted for $72 \mathrm{~h}$, then allowed to cool to room temperature. The internal pressure inside the autoclave was measured and the solvothermal product was recovered and stored under nitrogen atmosphere. Because solvothermal products are unstable in air, characterizations were carried out as fast as possible, keeping the product under inert atmosphere as long as possible.

\section{B.2. Characterizations}

Raman spectroscopy investigations were conducted with a Renishaw inVia Quontor equipped with a $532 \mathrm{~nm}$ laser operating in the spectral range of $100-3600 \mathrm{~cm}^{-1}$ in synchroscan mode. HEP was simply poured inside a watch glass and the laser beam was focused just under the surface of the liquid. Solvothermal products were kept inside sealed silica quartz cells to avoid any contact with air.

X-Ray diffraction (XRD) was performed on a Bruker D8 Advance diffractometer using $\mathrm{Mo}(\mathrm{K} \alpha 1)$ radiation with $\lambda=$ $0.70930 \AA$ Å. Analysed samples were introduced in $1.5 \mathrm{~mm}$ wide Lindemann glass capillaries under nitrogen (Air Liquide, Alphagaz 2) atmosphere. 
In situ mass spectrometry was carried out using a solvothermal reactor directly connected to a mass spectrometer (Pfeiffer Vacuum Prisma). The pressure in the entire device was controlled at the desired level using a set of valves. Measured intensities were normalized to the $\mathrm{N}_{2}$ peak (channel 28) in order to perform proper comparisons throughout the analysis without influence from slight changes in the measured gas flow.

Molecular masses in the range $0-120 \mathrm{~g} \mathrm{~mol}^{-1}$ were investigated, with no peaks identifiable above this limit. Compound identification was achieved using the National Institute of Standards and Technology (NIST) library as a reference.

\section{Results and discussion}

\section{C.1. Pressure and reaction yield investigations}

Regarding the stoichiometry generally considered for the reaction between sodium and an alcohol (eqn (1)), the reaction yield and released pressure can be calculated. Here, EP stands for 1-ethylpiperidine.

$$
\mathrm{HEP}+\mathrm{Na} \rightarrow \mathrm{EP}-\mathrm{ONa}+1 / 2 \mathrm{H}_{2}
$$

Because sodium is always introduced in the same or higher quantity than HEP, the latter will be considered as limiting in eqn (1). Considering the total reaction, the final molar amount of EP-ONa is then equal to the initial HEP molar amount. The amount of $\mathrm{H}_{2}$ produced is equal to half that of HEP initially introduced, i.e. $0.087 \mathrm{~mol}$ here. The reaction yield was defined as the ratio between the amount of solvothermal product recovered over the maximum amount of EP-ONa that could be obtained, taking into account the excess sodium introduced.

The theoretical pressure released by the formation of $\mathrm{H}_{2}$ was estimated using the ideal gas law. Considering the volume of the solvothermal reactor, the theoretical partial pressure of hydrogen at room temperature $(293 \mathrm{~K})$ was calculated as 4.24 bar $\left(4.24 \times 10^{5} \mathrm{~Pa}\right)$. The overpressures displayed in Table 1 and Fig. 1 result from the difference between the pressure of $\mathrm{N}_{2}$ injected at room temperature before heating and the final pressure measured at room temperature after the reaction.

In this study, the impacts of three parameters were investigated, namely solvothermal reaction temperature and pressure and the molar ratio between sodium and HEP. Table 1 summarizes the operating conditions considered and elements of the products obtained. The uncertainty of the pressure measurements was estimated at \pm 1 bar. As full recovery of the solvothermal product from the reactor can be troublesome because of its high viscosity, the loss of solvothermal product was estimated to be lower than $1 \mathrm{~g}$, leading to an uncertainty in the reaction yield near $\pm 5 \mathrm{wt} \%$. Please note that runs SP-T/350 and SP-R/1.5 as well as SP-T/380 and SP-P/200 are strictly identical but have been given different names for the sake of clarity.

The reaction yields and overpressures are reported in Fig. 1. Theoretical $\mathrm{H}_{2}$ partial pressure as calculated from eqn (1) was added to evidence the difference in pressure between theory and experiment.

The obtained results are interesting in many aspects. First, the overpressure before opening the solvothermal reactor at ambient temperature was found in all cases to be larger than the theoretical hydrogen overpressure, expressing the fact that the postulated reaction in eqn (1) cannot be the only chemical process; other reactions leading to the formation of gas species must occur.

Second, the overpressure value can be correlated to the reaction operating conditions. An increase in the solvothermal reaction temperature causes an elevation of the overpressure, from $4 \pm 1$ bar to $12 \pm 1$ bar at $300{ }^{\circ} \mathrm{C}$ and $380{ }^{\circ} \mathrm{C}$, respectively, with a slight decrease between $350{ }^{\circ} \mathrm{C}$ and $380{ }^{\circ} \mathrm{C}$ (Fig. 1(a)). This increase in pressure could be due to the promotion of gascreating reactions at higher temperatures compared to lower ones. In contrast, an increase in the $\mathrm{Na} / \mathrm{HEP}$ ratio at constant temperature results in a reduction in the overpressure, from $14 \pm 1$ bar to $11 \pm 1$ bar for Na/HEP ratios of 1.0 and 2.0, respectively (Fig. 1(b)). Addition of sodium could reduce the overpressure by reacting with the gas phase and/or hinder the reactions leading to the formation of gaseous species. A decrease in overpressure is also observed with a larger solvothermal reaction pressure, from $18 \pm 1$ bar to $12 \pm 1$ bar at 100 bar and 200 bar, respectively (Fig. 1(c)). The less significant gas phase formation can simply be explained by Le Chatelier's principle and has been previously reported in literature as a compression effect, ${ }^{37}$ being mostly favourable to the creation of denser structures.

Finally, the reaction yields always ranged from $60 \mathrm{wt} \%$ to $70 \mathrm{wt} \%$. However, in a sealed reactor every loss of matter must result in the formation of another product, either in solid, liquid or gaseous state. Different hypotheses have been expressed and tested to explain the observed loss of matter. A direct relation between the overpressure and the low yields was considered first. This overpressure could be due to the release of light molecules,

Table 1 Sample identifications, reaction parameters and experimental results

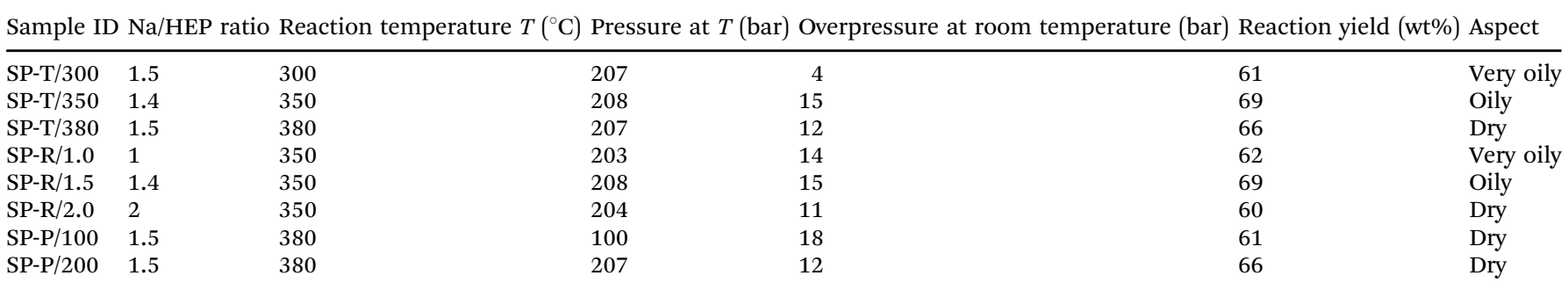


(a)

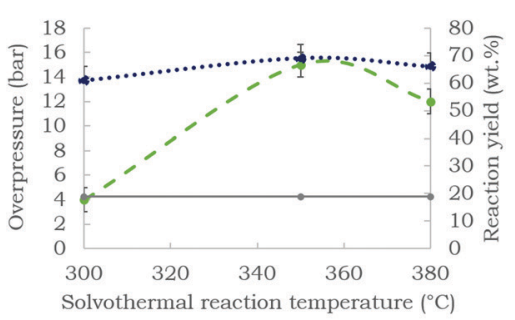

(b)

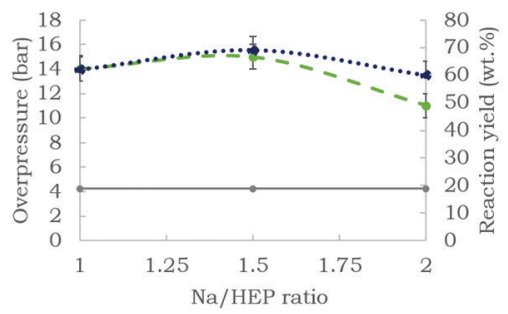

(c)

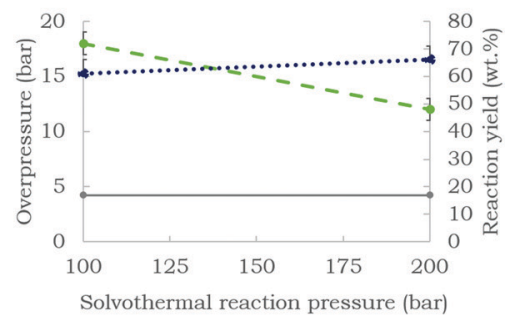

Fig. 1 Theoretical gas overpressure (grey line), experimental gas overpressure (green dashed line) and yield (dark blue dotted line) with the evolution of the solvothermal reaction temperature (a), Na/HEP ratio (b) and solvothermal reaction pressure (c).

e.g. $\mathrm{H}_{2}, \mathrm{CH}_{4}$, or $\mathrm{H}_{2} \mathrm{O}$, from the degradation of the solvothermal product. However, the low molar masses of such molecules do not suffice to explain the observed mass loss. Formation of heavier molecules could also be imagined, such as the oxidation products $\mathrm{CO}, \mathrm{NO}, \mathrm{CO}_{2}$ or $\mathrm{NO}_{2}$. In this case, a relationship between the overpressure and the mass loss could be established. However, the initial amount of oxygen atoms inside the reactor is insufficient to produce such amounts of carbon or nitrogen oxides. Formation of volatile organic compounds could be envisaged, but it is unlikely that their volatility would correspond to overpressures over 10 bar at room temperature.

Regarding the obtained results and calculations, a direct correlation between the gas and solid phases does not fully explain the losses of mass in the solid phase. After cooling and measurement of the gas pressure, solvothermal products were recovered and calculations of reaction yields were achieved, but only after opening the reactor and subsequent release of part of the gas phase; a loss of matter due to the sudden decompression is likely and may explain the yields usually below $70 \mathrm{wt} \%$. This phenomenon will be further discussed later in this paper.

Solvothermal products can also be visually characterized by their physical aspects and more especially their oily aspect. As this introduced parameter is difficult to quantify, also because of their instability in air, a qualitative approach has been taken using three different designations. The first is "very oily" and has been applied to samples presenting a liquid phase, often presenting a brownish colour. The second is "oily" and has been given to samples containing a unique solid phase but susceptible to leaving oily traces on the glass flask. The last is "dry" and corresponds to powdery samples leaving no oily trace in their flasks. Photographs illustrating these are presented in Fig. 2.

These aspects of the solvothermal products are given in Table 1 along with the reaction conditions. Solvothermal products range from very oily to oily and then dry by increasing the temperature or the $\mathrm{Na} / \mathrm{HEP}$ ratio.

At $300{ }^{\circ} \mathrm{C}$, liquid compounds are present in high quantities in comparison to the solids formed. When increasing the temperature to $350{ }^{\circ} \mathrm{C}$, this liquid phase appears partly replaced by a solid phase, the latter becoming preponderant upon further increase to $380{ }^{\circ} \mathrm{C}$. This phenomenon could be explained either by thermal decomposition or thermally favoured conversion reactions. A slight change of colour, from brown to perfectly black, was also observed
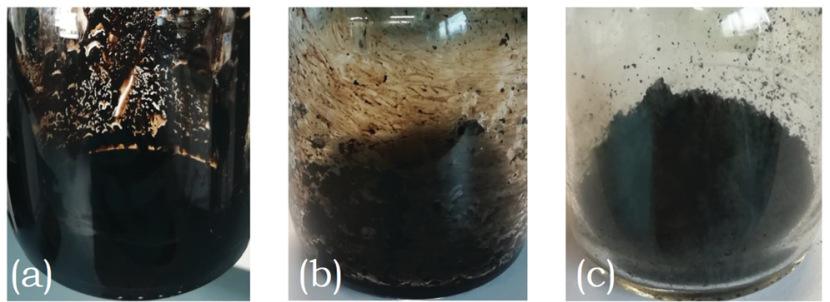

Fig. 2 Photographs of solvothermal products presenting a very oily aspect (a), oily aspect (b) and dry aspect (c).

with the increase in temperature, indicating that the solvothermal product obtained at $380{ }^{\circ} \mathrm{C}$ is likely more carbon-rich than the one obtained at $300{ }^{\circ} \mathrm{C}$, especially with a larger density of conjugated double bonds.

Similar observations were made upon an increase in Na/HEP ratio from 1.0 to 2.0, except for the colour remaining dark brownish for the powdery sample SP-R/2.0. The less marked oily aspect can be attributed to the higher number of possible reactions with $\mathrm{Na}$, which is present in greater excess as the $\mathrm{Na} / \mathrm{HEP}$ ratio increases. Thus, the liquid phase is more likely to react with the available sodium to give solid sodium compounds such as $\mathrm{NaOH}$ or $\mathrm{Na}_{2} \mathrm{CO}_{3}$. No visible change was observed with the increase in solvothermal reaction pressure, this parameter being possibly less critical in the range investigated than solvothermal reaction temperature or $\mathrm{Na} / \mathrm{HEP}$ ratio. Pressures above 100 bar do not seem to be determinant to the formation of dry compounds. However, experiments not presented here showed that a 100 bar pressure leads, after a pyrolysis step, to poor quality $\mathrm{N}$-doped graphenic foams.

\section{C.2. Gas phase characterization: mass spectrometry investigations}

In situ mass spectrometry was used to investigate the gas phase throughout a typical solvothermal reaction, carried out at $380^{\circ} \mathrm{C}$ and 200 bar with a Na/HEP ratio of 1.5 . These conditions were chosen as they are known to produce the graphenic material with the highest quality after thermal post-treatment (data not shown here). Channels of interest are plotted over reaction time in Fig. 3. The log scale was used in the plots because of the large range in order of magnitude of the signal. The in situ analysis was preceded by a blank test, without reagents introduced in the reactor, which takes into account 
the impurities in the glove bag atmosphere, such as traces of $\mathrm{O}_{2}, \mathrm{CO}_{2}$ and $\mathrm{H}_{2} \mathrm{O}$. Values from the blank analysis were added in the form of orange dotted lines in Fig. 3(a-e).

Analysis of the collected data shows a fast change in the gaseous phase composition within the first hours of the reaction. A large increase in the intensity of channel 2 (Fig. 3(a)), related to $\mathrm{H}_{2}$, coupled with the appearance of peaks at $m / z=98$, 99, 84 and 85 (Fig. 3(f)), associated with solvothermal alkoxide EP-ONa fragments, demonstrate the occurrence of the reaction between Na and HEP (eqn (1)). Moreover, since the intensities of both $\mathrm{H}_{2}$ and EP-ONa channels tend to stabilize after a few hours, it is likely that this reaction is either completed or reaches a steady level within this time.

Signal intensities of channels 15, 17 and 44 (Fig. 3(b, c and e)), related to $\mathrm{CH}_{4}, \mathrm{NH}_{3}$ and $\mathrm{CO}_{2}$, respectively, increased rapidly in the first hours of the synthesis. This shows the occurrence of secondary reactions which are likely responsible for the increase in the final gas pressure discussed in the previous part.

$\mathrm{CH}_{4}$ intensity increased around 40-fold in the first hours, followed by a steady but far slower increase with time; the intensity was three times higher at the end of the run (4300 min) than at $220 \mathrm{~min}$. The steady rise in $\mathrm{CH}_{4}$ could be related to the thermal degradation of the solid phase, rich in carbon atoms, throughout the synthesis. Additionally, methanation reactions are highly suspected to occur, as high pressures and the temperature domain investigated are known to favour $\mathrm{CO}$ and $\mathrm{CO}_{2}$ conversion to $\mathrm{CH}_{4} \cdot{ }^{38}$ Methane formation usually occurs through a set of four main gas-phase reactions, involving reverse water-gas shift (eqn (2)), CO methanation (eqn (3)), reverse dry reforming (eqn (4)) and $\mathrm{CO}_{2}$ methanation (eqn (5)). ${ }^{39}$ Formation of $\mathrm{CO}$ could not be followed since its molecular weight $(\mathrm{m} / \mathrm{z}=28)$ is the same as that of $\mathrm{N}_{2}$, a major component in the gas phase.

$$
\begin{gathered}
\mathrm{CO}_{2}+\mathrm{H}_{2} \rightleftharpoons \mathrm{CO}+\mathrm{H}_{2} \mathrm{O} \\
\mathrm{CO}+3 \mathrm{H}_{2} \rightleftharpoons \mathrm{CH}_{4}+\mathrm{H}_{2} \mathrm{O} \\
2 \mathrm{CO}+2 \mathrm{H}_{2} \rightleftharpoons \mathrm{CH}_{4}+\mathrm{CO}_{2} \\
\mathrm{CO}_{2}+4 \mathrm{H}_{2} \rightleftharpoons \mathrm{CH}_{4}+2 \mathrm{H}_{2} \mathrm{O}
\end{gathered}
$$

Channel 18, related to $\mathrm{H}_{2} \mathrm{O}$, was also plotted (Fig. 3(d)). No evident trend could be observed except a slight decrease with time. However, water was detected in the same order of magnitude as in the blank measurement; it therefore appears not certainly representative of real changes in the gaseous phase. However, water formation followed by its fast reaction
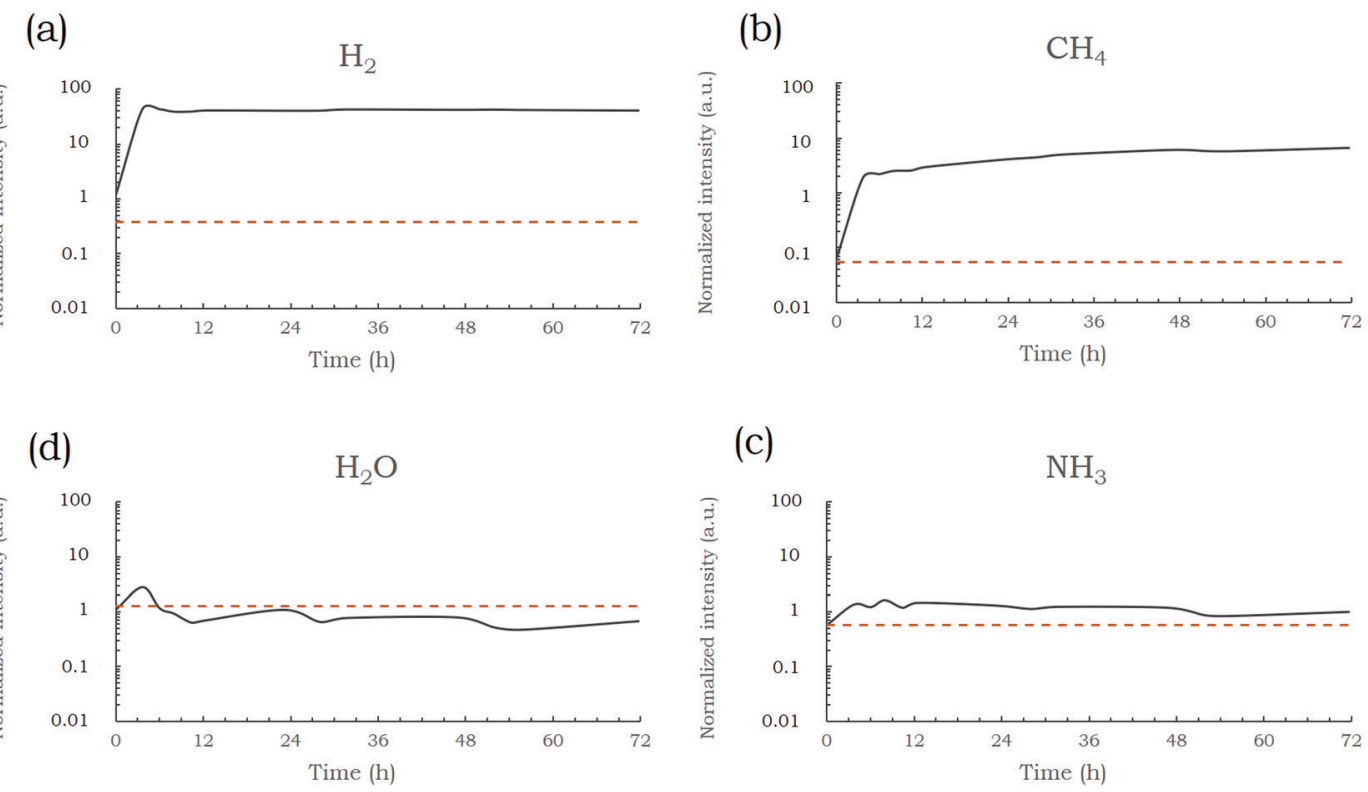

(e)
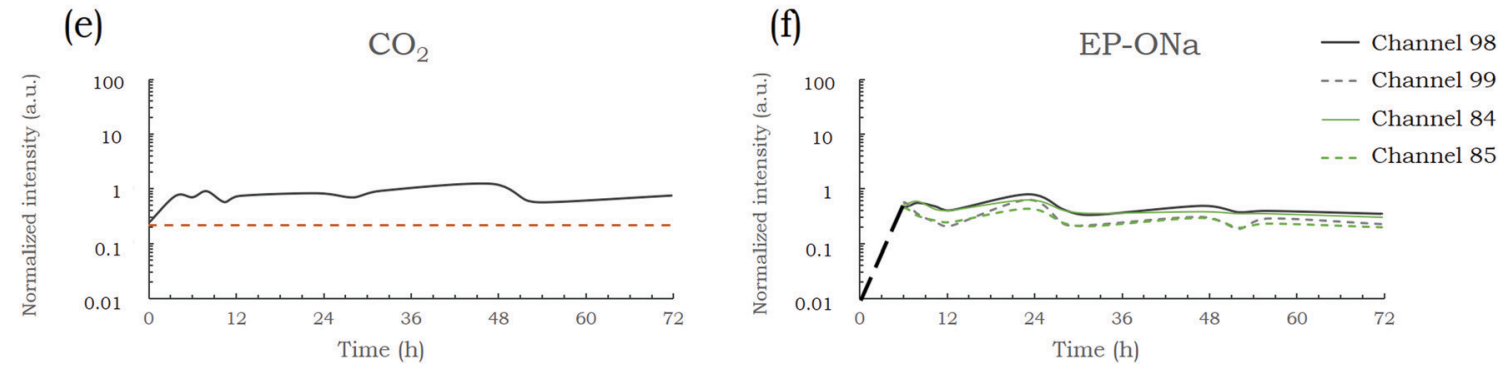

Fig. 3 Time variation of channel signals associated with $\mathrm{H}_{2}$ (a), $\mathrm{CH}_{4}$ (b), $\mathrm{NH}_{3}(\mathrm{c}), \mathrm{H}_{2} \mathrm{O}$ (d), $\mathrm{CO}_{2}$ (e) and solvothermal alkoxide EP-ONa (f); the orange dotted lines are the signals from the blank test; the black dashed line has been added on the EP-ONa graph to better visualize the appearance of this product; solvothermal conditions: $380^{\circ} \mathrm{C}, 200$ bar, Na/HEP ratio 2.0. 
with $\mathrm{Na}$ excess-resulting in low steady $\mathrm{H}_{2} \mathrm{O}$ content-could not be excluded.

Besides, thermodynamic calculations made on the simple $\mathrm{N}_{2}-\mathrm{H}_{2}$ system showed that a significant part of the introduced nitrogen can react with dihydrogen to form ammonia from approx. 3.6 bar at $300{ }^{\circ} \mathrm{C}$ to 2.7 bar at $380{ }^{\circ} \mathrm{C}$ under 200 bar of total pressure. ${ }^{40}$ Although conducted considering a simpler system than that in the solvothermal reactor, these calculations demonstrated the likely formation of ammonia during the process.

\section{C.3. Solid phase characterization}

C.3.1. X-ray diffraction investigations. In order to further understand what species or bond could be formed during the solvothermal reaction, X-ray diffraction (XRD) was carried out on sample SP-T/350 (identical to SP-R/1.5). This sample being median in terms of solvothermal reaction temperature and $\mathrm{Na}$ /HEP ratio, every possible solid-state phase is expected to be present on its diffractogram, which is shown in Fig. 4. The majority of its diffraction peaks were indexed as sodium compounds, such as sodium carbonate $\mathrm{Na}_{2} \mathrm{CO}_{3}$, sodium hydride $\mathrm{NaH}$, sodium cyanide $\mathrm{NaCN}$ and sodium hydride cyanamide $\mathrm{Na}_{5} \mathrm{H}\left(\mathrm{CN}_{2}\right)_{3}$. No peaks related to a crystalline carbon phase can be observed due to the lack of organization in the carbon-based network at this early stage of the synthesis. XRD data allow identification of the type of environment created during the solvothermal process. It is observed here that sodium does not only react with HEP but could also be involved in many secondary reactions. Sodium compounds are good indicators of the formation of the various molecules generated by HEP degradation. For instance, the presence of $\mathrm{Na}_{2} \mathrm{CO}_{3}$ likely reveals the formation of $\mathrm{H}_{2} \mathrm{O}$ and $\mathrm{CO}_{2}$, according to eqn (6)-(8).

$$
\begin{gathered}
\mathrm{Na}+\mathrm{H}_{2} \mathrm{O} \rightarrow\left(\mathrm{Na}^{+} \mathrm{OH}^{-}\right)+1 / 2 \mathrm{H}_{2} \\
2 \mathrm{OH}^{-}+\mathrm{CO}_{2} \rightarrow \mathrm{CO}_{3}^{2-}+\mathrm{H}_{2} \mathrm{O}
\end{gathered}
$$

$$
2 \mathrm{Na}^{+}+\mathrm{CO}_{3}^{2-} \rightarrow \mathrm{Na}_{2} \mathrm{CO}_{3}
$$

$\mathrm{H}_{2}$, once formed, can also react with sodium to form the sodium hydride revealed by XRD, according to eqn (9), as suggested by Speyer et al. ${ }^{15}$

$$
\mathrm{Na}+1 / 2 \mathrm{H}_{2} \rightarrow \mathrm{NaH}
$$

Sodium cyanide can be formed through different pathways. Each involves the earlier formation of simple molecules such as $\mathrm{NaNH}_{2}$ or HCN, as in eqn (10) and (11). ${ }^{41,42}$

$$
\begin{gathered}
\mathrm{NaNH}_{2}+\mathrm{C} \rightarrow \mathrm{NaCN}+\mathrm{H}_{2} \\
\mathrm{HCN}+\mathrm{NaOH} \rightarrow \mathrm{NaCN}+\mathrm{H}_{2} \mathrm{O}
\end{gathered}
$$

$\mathrm{NaNH}_{2}$ can be formed by the reaction of sodium with ammonia, ${ }^{43}$ while HCN can be produced via the reaction of methane with ammonia, according to the Degussa (eqn (12)) and Andrussow (eqn (13)) processes. ${ }^{44}$

$$
\begin{gathered}
\mathrm{Na}+\mathrm{NH}_{3} \rightarrow \mathrm{NaNH}_{2}+1 / 2 \mathrm{H}_{2} \\
\mathrm{CH}_{4}+\mathrm{NH}_{3} \rightarrow \mathrm{HCN}+3 \mathrm{H}_{2}
\end{gathered}
$$

The thermal decomposition of sodium hydride cyanamide $\mathrm{Na}_{5} \mathrm{H}\left(\mathrm{CN}_{2}\right)_{3}$ during solvothermal reaction, revealed by the XRD indexation, might lead to the formation of NaCN during the solvothermal process. In the literature, the decomposition of sodium cyanamide $\mathrm{Na}_{2} \mathrm{CN}_{2}$ has been shown to yield $\mathrm{NaCN}$, Na and $\mathrm{N}_{2},{ }^{45}$ in accordance with eqn (14).

$$
\mathrm{Na}_{2} \mathrm{CN}_{2} \rightarrow 2 \mathrm{NaCN}+\mathrm{Na}+\mathrm{N}_{2}
$$

It is suggested here that a similar reaction could occur during the solvothermal process starting from $\mathrm{Na}_{5} \mathrm{H}\left(\mathrm{CN}_{2}\right)_{3}$. However, the formation of $\mathrm{Na}_{5} \mathrm{H}\left(\mathrm{CN}_{2}\right)_{3}$ during the solvothermal reaction is not yet well understood.

C.3.2. Raman spectroscopy investigations. Raman spectroscopy has been used here to better characterize the solvothermal product in terms of the density of $\pi$-conjugated bonds. For the

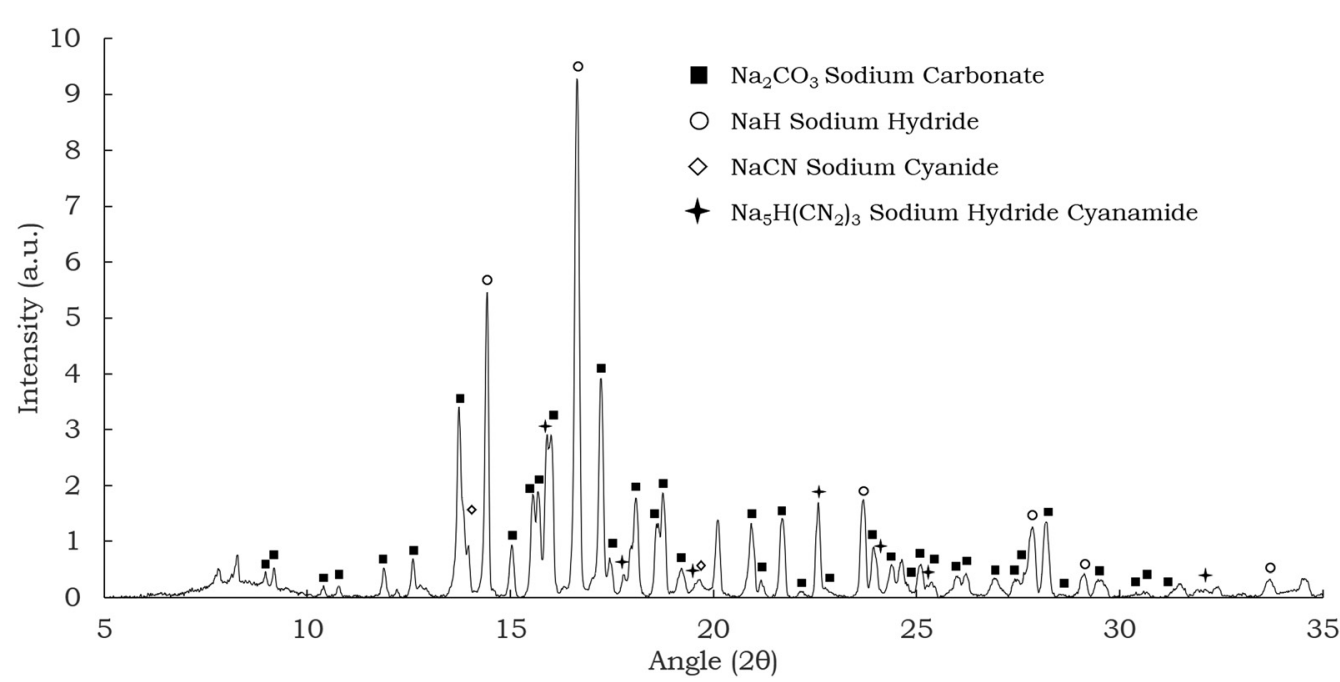

Fig. 4 X-ray diffractogram of solvothermal product SP-T/350, indexed with sodium carbonate (PDF 37-0451), sodium hydride (PDF 76-0171), sodium cyanide (PDF 37-1490) and sodium hydride cyanamide (PDF 89-1367). 


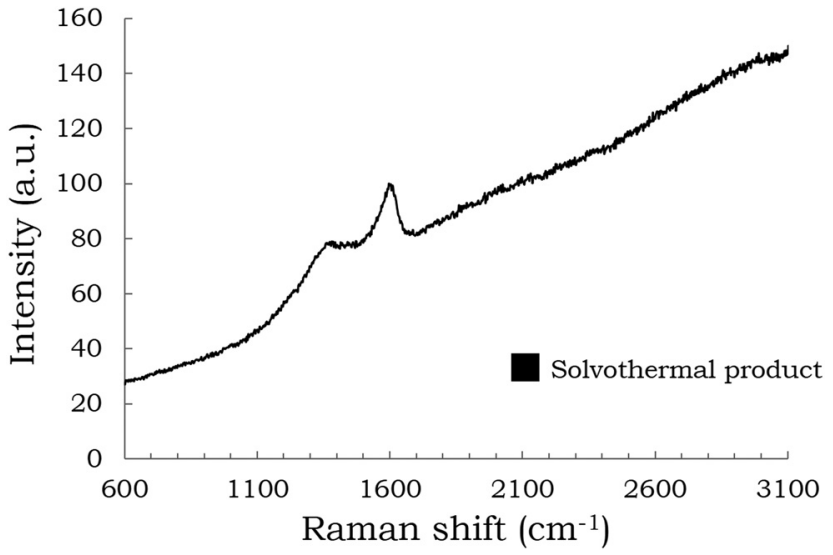

Fig. 5 Raman spectrum of the solvothermal product.

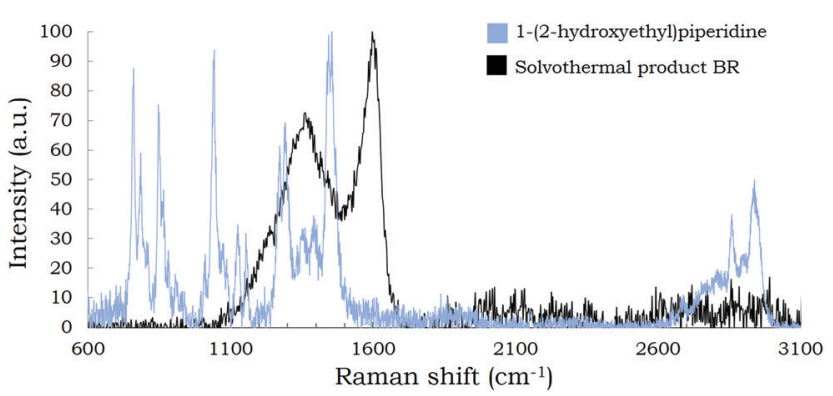

Fig. 6 Raman spectra of HEP (blue) and the solvothermal product BR (black).

sake of comparison, spectra of HEP and sample SP-T/350 were recorded in the range $600-3100 \mathrm{~cm}^{-1}$ using a $532 \mathrm{~nm}$ wavelength laser (Fig. 5 and 6).

Two interesting features in the form of two large bands appear on the solvothermal product spectrum at $1374 \mathrm{~cm}^{-1}$ and $1605 \mathrm{~cm}^{-1}$, corresponding respectively to the well-known D and $\mathrm{G}$ carbon bands. ${ }^{4-48} \mathrm{~A}$ high content of organized $\mathrm{sp}^{2}$ carbon atoms is thus likely to be present after the solvothermal reaction as indicated by the $\mathrm{G}$ band, with the intense and broad $\mathrm{D}$ band indicating the presence of numerous defects, such as amorphous carbon, aliphatic fraction or defects in the graphenic network. The strong fluorescent background indicates the existence of high molecular weight aromatic molecules, with a high number of $\pi$-conjugated bonds. The more conjugated the $\pi$-system, the higher the Raman shift towards high wavelengths. For the sake of clarity, the fluorescent background has been removed using computational tools to give the spectrum referred to as solvothermal product BR (background removed).

The HEP spectrum shown in Fig. 6 displays many characteristic bands in the studied range, none of which are present in the solvothermal product BR spectrum. From this observation, the conversion of HEP during the solvothermal process appears total.

\section{Proposed overall mechanism}

The first part of this work shows the broad source of information obtained on the solvothermal reaction between sodium and 1-(2-hydroxyethyl)piperidine using complementary analytical techniques. It was first observed that after each solvothermal reaction, an overpressure and loss of mass were noticed. It has been shown that a direct correlation between these two phenomena cannot explain the observations. Therefore, the occurrence of several reactions was suggested from the results of mass spectroscopy and XRD investigations, mainly linked to the thermal degradation of HEP and EP-ONa into smaller molecules such as $\mathrm{CO}_{2}, \mathrm{H}_{2} \mathrm{O}$ or $\mathrm{CH}_{4}$, as well as reactions between the excess sodium and various species. Raman spectroscopy revealed the early formation of $\mathrm{sp}^{2}$ hybridized carbon atoms in both graphitic domains and large aromatic molecules. The second part of this work aims to build bridges between these results to propose an overall mechanism for the solvothermal reaction.

\section{D.1. Reaction pathway}

D.1.1. First reaction stage. Based on the in situ mass spectrometry observations, the expected reaction between HEP and Na (eqn (1)) is likely to start as soon as the reagents are put into contact. The stabilization of the channels related to $\mathrm{H}_{2}$ and EP-ONa after a few hours indicated a nearly terminated reaction. Moreover, the total conversion of HEP to EP-ONa was confirmed by Raman spectroscopy, as no traces of the initial reagent were detected in the final product.

The large increase in $\mathrm{H}_{2}$ concentration (related to eqn (1)) within the first hours is accompanied by a significant elevation in the $\mathrm{CO}_{2}, \mathrm{CH}_{4}$ and $\mathrm{NH}_{3}$ levels. The formation of these products can be assigned to the thermal degradation of EPONa, methanation reactions or reactions within the gaseous phase, e.g. ammonia formation from $\mathrm{N}_{2}$ and $\mathrm{H}_{2}$.

D.1.2. Second reaction stage. Throughout the entire solvothermal reaction, sodium can react with numerous molecules, e.g. $\mathrm{H}_{2}, \mathrm{H}_{2} \mathrm{O}, \mathrm{CH}_{4}$, and $\mathrm{NH}_{3}$, leading to the formation of numerous solid molecules, such as $\mathrm{NaH}, \mathrm{Na}_{2} \mathrm{CO}_{3}, \mathrm{NaCN}, \mathrm{NaOH}$ and $\mathrm{NaNH}_{2}$. These secondary reactions are of importance as they allow the conversion of the liquid phase, supposedly formed from a mixture of $\mathrm{H}_{2} \mathrm{O}, \mathrm{NH}_{3}$ and various $\mathrm{C}_{x} \mathrm{H}_{y}$ molecules, and part of the gaseous phase into a solid phase. As a matter of fact, it has been observed that for a Na/HEP ratio equal to unity, the conversion of liquid products is far from complete, as shown by the very oily aspect of the recovered product. In contrast, for higher $\mathrm{Na} / \mathrm{HEP}$ ratios, the fraction of liquid converted to a solid phase increases.

Meanwhile, the solid phase, mainly composed of carbon, nitrogen and oxygen atoms, undergoes rearrangement reactions promoting the formation of large aromatic molecules with a high number of $\pi$-conjugated bonds as well as $\mathrm{sp}^{2}$ carbon networks. Elimination reactions are likely to occur, as they become predominant over substitution reactions at high temperatures and under alkaline conditions. ${ }^{49}$ Condensation reactions, aromatization reactions and cyclization reactions are likely to take place during the solvothermal process.

\section{D.2. Description of the solvothermal products}

At the end of the solvothermal reaction, before the opening of the reactor, the solid phase composed of a carbon-based 


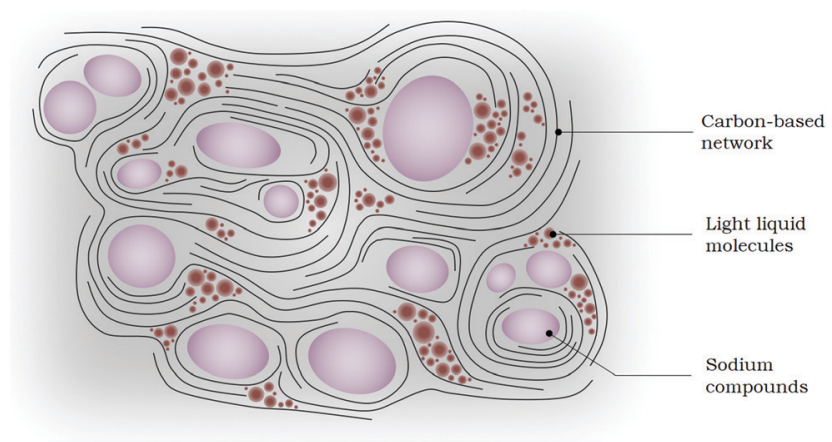

Fig. 7 Illustration of the proposed structure for the solvothermal solid product before opening the reactor.

network is likely to entrap solid sodium compounds and liquid or gaseous small molecules (Fig. 7). The gaseous phase contains most of the initial $\mathrm{N}_{2}$ injected before heating the reactor, as well as $\mathrm{H}_{2}, \mathrm{NH}_{3}, \mathrm{CO}_{2}, \mathrm{CH}_{4}$ and probably other light $\mathrm{C}_{x} \mathrm{H}_{y}$ molecules. The overall gases formed during the reaction are responsible for the increase in pressure, as reported in Table 1.

When the reactor is opened, the sudden change in pressure, from around 75-85 bar to atmospheric pressure, is likely to cause the vaporization or sublimation of some of the entrapped light molecules, which are ejected from the reactor. The presence of these molecules is not taken into account when measuring the pressure or when measuring the mass amount. This phenomenon could explain the calculated yields below $70 \mathrm{wt} \%$.

\section{E. Conclusions}

The solvothermal reaction between metallic sodium and 1-(2hydroxyethyl)piperidine yields a carbon-rich product, whose pyrolysis at $850{ }^{\circ} \mathrm{C}$ has been previously shown to lead to appealing 3-dimensional $\mathrm{N}$-doped graphenic materials. In the present study, the impact of the solvothermal temperature and pressure and the molar ratio between $\mathrm{Na}$ and HEP were investigated. An increase in temperature from $300{ }^{\circ} \mathrm{C}$ to $380{ }^{\circ} \mathrm{C}$ was shown to promote the conversion of the liquid phase into solid and gaseous compounds. It can be assumed that at high temperature, elimination reactions as well as other rearrangement reactions are more predominant than at lower temperatures. A rise in the Na/HEP ratio from 1.0 to 2.0 was revealed to contribute to various reactions between the excess sodium and small molecules, e.g. $\mathrm{CH}_{4}, \mathrm{NH}_{3}$ or $\mathrm{H}_{2} \mathrm{O}$. Change in pressure from 100 bar to 200 bar was not associated with meaningful variation in the solvothermal product. However, as was mentioned in a previous work, ${ }^{33}$ the pyrolysis of solvothermal products from 100 bar reactions led to only poorly organized graphenic materials. This could mean that the solvothermal pressure has an impact on the structure and microstructure of the solvothermal product, but it could not be investigated as the synthetized products are unstable under the electronic beam.

Complementary characterization techniques were carried out to understand how the solvothermal reaction proceeds. In situ mass spectrometry showed the formation of $\mathrm{H}_{2}, \mathrm{CH}_{4}$,
$\mathrm{NH}_{3}$, and $\mathrm{CO}_{2}$ throughout the synthesis, linked with the reaction between HEP and $\mathrm{Na}$, methanation reactions, and possible thermal degradation. The presence of these small molecules was successfully related to the XRD results, revealing the formation of various sodium compounds such as $\mathrm{Na}_{2} \mathrm{CO}_{3}$, $\mathrm{NaH}$ or NaCN. Raman spectroscopy demonstrated the early formation of a large $\mathrm{sp}^{2}$ carbon network as well as molecules containing numerous $\pi$-conjugated bounds.

The various sources of data collected led to an overall mechanism proposal which can hopefully help to better understand this type of reaction under strongly alkaline conditions, in a temperature and pressure domain still little known in organic synthesis. The schematic development still remains incomplete, in particular because of the complexity and diversity of the phases present. Further work will require more thorough analysis of the oils and tars formed, as has been performed for the middle temperature range conversion of biomass, for instance. The link between the solvothermal mixture and the highly structured products formed after pyrolysis is currently being investigated and will be thoroughly treated in a further paper. The preliminary results tend to show that the pressure inside the reactor plays a role in the porous structure of the graphenic foams, with low pressures being more favourable to the appearance of higher porosity, at the cost of lower crystallinity. On the other hand, the reaction temperature seems linked to the chemical composition of the graphenic foams, as well as their crystallinity and porosity. A break in trends seems to occur between the properties of the graphenic foams from the solvothermal reaction temperatures of $350{ }^{\circ} \mathrm{C}$ and $380{ }^{\circ} \mathrm{C}$. This observation may indicate the transition from a subcritical reaction to a supercritical reaction. Further investigations will be carried out to clarify this hypothesis.

\section{Conflicts of interest}

There are no conflicts to declare.

\section{Acknowledgements}

This work was supported partly by the French PIA project "Lorraine Université d'Excellence”, reference ANR-15-IDEX-04-LUE.

\section{Notes and references}

1 C. Aymonier, A. Loppinet-Serani, H. Reverón, Y. Garrabos and F. Cansell, J. Supercrit. Fluids, 2006, 38, 242-251.

2 C. Erkey, Supercritical Fluid Science and Technology, Elsevier, 2011, vol. 1, pp. 11-19.

3 N.-W. Pu, C.-A. Wang, Y. Sung, Y.-M. Liu and M.-D. Ger, Mater. Lett., 2009, 63, 1987-1989.

4 D. Rangappa, K. Sone, M. Wang, U. K. Gautam, D. Golberg, H. Itoh, M. Ichihara and I. Honma, Chem. - Eur. J., 2010, 16, 6488-6494.

5 L. Baldino, M. Sarno, S. Cardea, S. Irusta, P. Ciambelli, J. Santamaria and E. Reverchon, Ind. Eng. Chem. Res., 2015, 54, 8147-8156. 
6 J. Yang, M. Wu, F. Chen, Z. Fei and M. Zhong, J. Supercrit. Fluids, 2011, 56, 201-207.

7 X. Zhang, Z. Sui, B. Xu, S. Yue, Y. Luo, W. Zhan and B. Liu, J. Mater. Chem., 2011, 21, 6494.

8 X. Wu, J. Zhou, W. Xing, G. Wang, H. Cui, S. Zhuo, Q. Xue, Z. Yan and S. Z. Qiao, J. Mater. Chem., 2012, 22, 23186.

9 K. Mase, H. Kondo, S. Kondo, M. Hori, M. Hiramatsu and H. Kano, Appl. Phys. Lett., 2011, 98, 193108.

10 S. P. Sasikala, P. Poulin and C. Aymonier, Adv. Mater., 2017, 29, 1605473.

11 Q. Kuang, S.-Y. Xie, Z.-Y. Jiang, X.-H. Zhang, Z.-X. Xie, R.-B. Huang and L.-S. Zheng, Carbon, 2004, 42, 1737-1741.

12 A. Eftekhari and P. Jafarkhani, J. Phys. Chem. C, 2013, 117, 25845-25851.

13 M. Choucair, P. Thordarson and J. A. Stride, Nat. Nanotechnol., 2009, 4, 30-33.

14 L. Speyer, S. Fontana, S. Cahen, J. Ghanbaja, G. Medjahdi and C. Hérold, Solid State Sci., 2015, 50, 42-51.

15 L. Speyer, S. Fontana, S. Ploneis and C. Hérold, Microporous Mesoporous Mater., 2017, 243, 254-262.

16 L. Speyer, S. Fontana, S. Cahen and C. Hérold, Mater. Chem. Phys., 2018, 219, 57-66.

17 H. Cui, J. Zheng, P. Yang, Y. Zhu, Z. Wang and Z. Zhu, ACS Appl. Mater. Interfaces, 2015, 7, 11230-11238.

18 P. Yan, J. Liu, S. Yuan, Y. Liu, W. Cen and Y. Chen, Appl. Surf. Sci., 2018, 445, 398-403.

19 J. Huang, J. Han, T. Gao, X. Zhang, J. Li, Z. Li, P. Xu and B. Song, Carbon, 2017, 124, 34-41.

20 M. Li, Z. Liu, F. Wang and J. Xuan, J. Energy Chem., 2017, 26, 422-427.

21 H. L. Tan, A. Du, R. Amal and Y. H. Ng, Chem. Eng. Sci., 2019, 194, 85-93.

22 J. Guo, S. Gadipelli, Y. Yang, Z. Li, Y. Lu, F. J. L. Brett and Z. Guo, J. Mater. Chem. A, 2019, 7, 3544-3551.

23 L. S. Panchakarla, K. S. Subrahmanyam, S. K. Saha, A. Govindaraj, H. R. Krishnamurthy, U. V. Waghmare and C. N. R. Rao, Adv. Mater., 2009, 21, 4726-4730.

24 Z. Wang, P. Li, Y. Chen, J. Liu, H. Tian, J. Zhou, W. Zhang and Y. Li, J. Mater. Chem. C, 2014, 2, 7396.

25 D. Li, X. Duan, H. Sun, J. Kang, H. Zhang, M. O. Tade and S. Wang, Carbon, 2017, 115, 649-658.

26 C. S. Ramirez-Barria, D. M. Fernandes, C. Freire, E. VillaroAbalos, A. Guerrero-Ruiz and I. Rodriguez-Ramos, Nanomaterials, 2019, 9, 1761.

27 Z. Xing, X. Luo, Y. Qi, W. F. Stickle, K. Amine, J. Lu and X. Ji, ChemNanoMat, 2016, 2, 692-697.
28 J. Moon, J. An, U. Sim, S.-P. Cho, J. H. Kang, C. Chung, J.-H. Seo, J. Lee, K. T. Nam and B. H. Hong, Adv. Mater., 2014, 26, 3501-3505.

29 X. Chen, D. Deng, X. Pan, Y. Hu and X. Bao, Chem. Commun., 2015, 51, 217-220.

30 D. Deng, X. Pan, L. Yu, Y. Cui, Y. Jiang, J. Qi, W.-X. Li, Q. Fu, X. Ma, Q. Xue, G. Sun and X. Bao, Chem. Mater., 2011, 23, 1188-1193.

31 R. Ma, X. Ren, B. Y. Xia, Y. Zhou, C. Sun, Q. Liu, J. Liu and J. Wang, Nano Res., 2016, 9, 808-819.

32 S. M. Lyth, Y. Nabae, N. Md. Islam, T. Hayakawa, S. Kuroki, M. Kakimoto and S. Miyata, e-J. Surf. Sci. Nanotechnol., 2012, 10, 29-32.

33 L. Moumaneix, S. Fontana, M. Dossot, F. Lapicque and C. Hérold, Microporous Mesoporous Mater., 2020, 300, 110165.

34 C. H. Tu, Chem. Eng. Sci., 1995, 50, 3515-3520.

35 J. Marrero and R. Gani, Fluid Phase Equilib., 2001, 183-184, 183-208.

36 J. Li, L. Xia and S. Xiang, Fluid Phase Equilib., 2016, 417, 1-6.

37 G. Demazeau, J. Phys.: Conf. Ser., 2010, 215, 012124.

38 S. Rönsch, J. Schneider, S. Matthischke, M. Schlüter, M. Götz, J. Lefebvre, P. Prabhakaran and S. Bajohr, Fuel, 2016, 166, 276-296.

39 K. Ghaib, K. Nitz and F.-Z. Ben-Fares, ChemBioEng Rev., 2016, 3, 266-275.

40 V. Kaiser, E. Filippi, H. D. Léger and P. Lesur, Techniques de l'ingénieur, 1999, J4 040, 1-16 [in French].

41 A. Rubo, R. Kellens, J. Reddy, N. Steier and W. Hasenpusch, Ullmann's Encyclopedia of Industrial Chemistry, Wiley-VCH Verlag GmbH \& Co. KGaA, Weinheim, Germany, 2006, DOI: 10.1002/14356007.i01_i01.

42 M. F. Ray and M. Rajchel, US 6649136B2, 2003.

43 K. W. Greenlee, A. L. Henne and W. C. Fernelius, in Inorganic Syntheses, ed. W. C. Fernelius, John Wiley \& Sons, Inc., Hoboken, NJ, USA, 2007, pp. 128-135.

44 E. Formentin and C. Schafer, EP 2260002B1, 2011.

45 M. J. Sole and A. D. Yoffe, Proc. R. Soc. London, Ser. A, 1964, 277, 523-539.

46 K. Sasaki, Y. Tokura and T. Sogawa, Crystals, 2013, 3, 120-140.

47 R. J. Nemanich and S. A. Solin, Phys. Rev. B: Condens. Matter Mater. Phys., 1979, 20, 392-401.

48 M. S. Dresselhaus, A. Jorio and R. Saito, Annu. Rev. Condens. Matter Phys., 2010, 1, 89-108.

49 L. P. Wolters, Y. Ren and F. M. Bickelhaupt, ChemistryOpen, 2014, 3, 29-36. 